\title{
OBSERVAÇÕES COMPORTAMENTAIS DO GAVIÃO-PATO Spizaetus melanoleucus (Accipitriformes, Accipitridae) NO ESTADO DO PARANÁ, BRASIL
}

Willian Menq ${ }^{1}$

MENQ, W. Observações comportamentais do gavião-pato Spizaetus melanoleucus (Accipitriformes, Accipitridae) no estado do Paraná, Brasil. Arq. Ciênc. Vet. Zool. UNIPAR, Umuarama, v. 18, n. 3, p. 175-178, jul./set. 2015.

RESUMO: O gavião-pato (Spizaetus melanoleucus) é uma ave de rapina florestal e naturalmente rara em toda sua distribuição. No estado do Paraná conta com registros escassos, especialmente na porção noroeste. Devido a suas baixas densidades populacionais e comportamento inconspícuo, são escassas as informações biológicas da espécie. O presente estudo apresenta alguns registros e observações comportamentais do S. melanoleucus em dois remanescentes florestais do interior do Paraná. As observações sugerem que a espécie pode forragear com certa frequência em áreas abertas a procura de mamíferos e outros pequenos vertebrados. Além disso, a espécie aparenta ser mais detectável em voo próximo ao final da manhã e início da tarde. Informações sobre a biologia, comportamento, estratégias de caça e distribuição da espécie podem ajudar a compreender melhor sua biologia e auxiliar estratégias de conservação.

PALAVRAS-CHAVE: Aves de rapina. Floresta Estacional Semidecidual. Reserva Biológica das Perobas.

\section{BEHAVIORAL OBSERVATIONS ON THE BLACK-AND-WHITE HAWK-EAGLE Spizaetus melanoleucus (Accipitriformes, Accipitridae) IN THE STATE OF PARANÁ, BRAZIL}

\begin{abstract}
The black-and-white hawk-eagle (Spizaetus melanoleucus) is a forest raptor and naturally rare throughout its distribution. In the state of Paraná, it has few records, especially in the northwest. Due to low population densities and inconspicuous behavior, there is little biological information available on the species. This study presents some records and behavioral observations on Spizaetus melanoleucus in two forest remnants in the countryside of the state of Paraná. Observations suggest that the species may often forage in open areas, seeking small mammals and other vertebrates. Moreover, the species seems to be more detectable in the late-morning and early afternoon flights. Information on the biology, behavior, hunting strategies and distribution of the species can help to better understand their biology and assist on conservation strategies.

KEYWORDS: Perobas Biological Reserve. Raptors. Semideciduous Forest.
\end{abstract}

\section{OBSERVACIONES DE COMPORTAMIENTO DEL AGUILA AZOR BLANQUINEGRA Spizaetus melanoleucus (Accipitriformes, Accipitridae) EN EL ESTADO DE PARANÁ, BRASIL}

RESUMEN: El águila azor blanquinegra (Spizaetus melanoleucus) es un ave de rapiña forestal y naturalmente rara en toda su distribución. En el estado de Paraná cuenta con registros escasos, especialmente en la parte noroeste. Debido a sus bajas densidades poblacionales y comportamiento discreto, son escasas las informaciones biológicas de la especie. Este estudio presenta algunos registros y observaciones de comportamiento del Spizaetus melanoleucus en dos remanentes forestales en el interior de Paraná. Las observaciones sugieren que la especie puede forrajear con poca frecuencia en áreas abiertas en busca de mamíferos y otros pequeños vertebrados. Además, la especie aparenta ser más detectable en vuelo próximo al final de la mañana e inicio de la tarde. Informaciones sobre la biología, comportamiento, estrategias de caza y distribución de las especies pueden ayudar a entender mejor su biología y auxiliar estrategias de conservación.

PALABRAS CLAVE: Aves de rapiña. Foresta Estacional Semidecidual. Reserva Biológica de las Perobas.

Introdução

O gavião-pato Spizaetus melanoleucus [Vieillot, 1816] é um accipitrídeo florestal de médio porte, possui de 51 a $58 \mathrm{~cm}$ de comprimento (SICK, 1997). Ocorre na região neotropical, apresenta uma ampla e descontínua distribuição, encontrado desde o México até a Argentina e por quase todo o Brasil (FERGUSON-LEES; CHRISTIE, 2001; SICK, 1997). Habita florestas primárias e secundárias, matas de galeria e porções mais arbóreas do cerrado. Alimenta-se principalmente de aves, como araçaris (Pteroglossus spp.), tucanos (Ramphastos spp.), papagaios, periquitos (Aratinga spp., Amazona spp.) e em menor frequência pequenos mamíferos e répteis (FERGUSON-LEES; CHRISTIE, 2001).
No Brasil, encontra-se ameaçado de extinção em todos os estados que estão sob domínio da Mata Atlântica (ALVES et al., 2000; MARQUES et al., 2002; MIKICH; BÉRNILS, 2004; SIMON et al., 2007; DRUMMOND et al., 2008; SILVEIRA et al., 2009). A exemplo de outras grandes aves de rapina, que são exclusivas de matas preservadas de consideráveis dimensões, o $S$. melanoleucus sofre principalmente com a perda e a fragmentação do habitat, além de ser alvo de caçadores e proprietários rurais, que costumam considerá-lo uma ameaça para as criações domésticas (MIKICH; BÉRNILS, 2004; PARANA, 2009).

No Paraná, registros de S. melanoleucus são escassos, parecendo ser um caso de raridade natural (MIKICH; BÉRNILS, 2004). A maioria dos registros estão concentra- 
dos em áreas sob domínio da Floresta Ombrófila densa da baixada litorânea e da Serra do Mar, e na Floresta Ombrófila mista do norte pioneiro e sul do Estado (ANJOS; SCHUCHMANN; BERNDT, 1997; STRAUBE; URBEN-FILHO, 2005), com poucos registros para a Floresta Estacional Semidecidual (SANTOS; COPATTI 2009; SIQUEIRA, 2011). Devido suas baixas densidades populacionais e comportamento inconspícuo, são escassas as informações biológicas da espécie.

Neste trabalho foram reunidas observações comportamentais do Spizaetus melanoleucus, obtidas de forma eventual, durante amostragens com a avifauna de aves de rapina em dois fragmentos florestais do estado do Paraná. Apesar das informações não terem sido obtidas de forma sistemática, estas podem ser de interesse para estudantes e pesquisadores, além de contribuir com o conhecimento sobre a espécie.

\section{Material e Métodos}

\section{Área de estudo:}

As observações de $S$. melanoleucus aqui apresentadas foram obtidas na Reserva Biológica das Perobas (RBP, $23^{\circ} 51$ ' 16 'S, $52^{\circ} 45$ ' 2 " W, $500 \mathrm{~m}$ de altitude; 8.716 ha) entre junho de 2009 e setembro de 2009 e abril de 2015, e na Fazenda Monte Alegre (FMA; $24^{\circ} 12^{\prime} 42^{~ ' S ~, ~ 50 ~ ' 33 ' 26 ~ “ W, ~}$ $700 \mathrm{~m}$ de altitude; $7.883 \mathrm{ha}$ ) em março de 2011 (ICMBIO 2012; REIS et al., 2006). A RBP localizada nos municípios de Tuneiras do Oeste e Cianorte é uma das maiores áreas de Floresta estacional semidecidual do sul do Brasil (ICMBIO 2012; MAGALHÃES; ORTÊNCIO-FILHO; DELARIVA, 2014). Já a FMA, localizada em Telêmaco Borba, está na zona de contato entre a floresta ombrófila mista e a floresta estacional semidecidual (RODERJAN et al., 2002).

\section{Procedimentos de campo:}

O registro da espécie nas duas áreas foi obtido por meio da técnica de pontos fixos (FULLER; MOSHER, 1987), o qual consiste no estabelecimento de pontos de observação alocados em áreas com boas condições a observação de gaviões (boa visibilidade acima do dossel da mata), com amostragens iniciando do amanhecer até as 15:00 $\mathrm{h}$, horário de maior detectabilidade de rapinantes diurnos (GRANZINOLLI; MOTTA-JUNIOR, 2008; MENQ; DELARIVA, 2015). A técnica contou com o auxílio de um binóculo $10 x 42$, câmera fotográfica com zoom óptico de 35 x, além de um gravador de voz digital, para documentação dos registros.

\section{Resultados}

Na RBP, o primeiro registro de $S$. melanoleucus foi realizado no dia 13 de junho de 2009, às 11:35 h, região leste do fragmento, em que um indivíduo adulto foi visualizado sobrevoando a mata e pousando no alto de uma peroba-rosa (Aspidosperma sp.). A ave permaneceu no local até ser acuada por meio de voos rasantes por um quiriquiri (Falco sparverius). Tal encontro foi relatado em artigo (SANTOS; COPATTI, 2009). No dia 27 de setembro de 2009, às 11:50 $\mathrm{h}$, outro indivíduo adulto, aparentemente um macho (pelo pequeno tamanho), foi avistado voando próximo à margem sul da reserva (Figura 1.a). O S. melanoleucus havia surgido da área aberta predominada por pastagem, voando a baixa altura e carregando uma presa (mamífero não-identificado) nas garras, sendo atacado por meio de voos rasantes por quatro gaviões-tesoura (Elanoides forficatus) e um sovi (Ictinia plumbea) que planavam no local. O terceiro encontro com a espécie na RBP foi obtido no dia 3 de abril de 2015, às 12:20 h, margem sul da floresta. $\mathrm{O}$ gavião levantou voo da mata e sobrevoou por cima do observador a grande altura e de maneira discreta, indo em direção à área de pastagem e desaparecendo em seguida.

Na FMA, foram realizadas uma série de observações do S. melanoleucus entre os dias 14 e 17 de março de 2011, todas entre os horários de 12:00 e 14:00 h. No dia 14 de março 2011 às 14:40 h, um indivíduo adulto foi observado sobrevoando uma área de campo próxima a floresta com uma presa nas garras, que foi identificada como sendo um preá (Cavia aperea) (Figura 1.b). No dia 15 de março, foi relatado um comportamento de caça da espécie. Na ocasião, foi observado o gavião voando rapidamente sobre o dossel da floresta e executando mergulhos pendulares com entradas na mata, diminuindo a velocidade sobre as copas, provavelmente a procura de presas. Nos dias seguintes, a espécie foi novamente avistada no local realizando o mesmo comportamento de caça.

Figura 1: Spizaetus melanoleucus em voo com um mamífero não identificado nas garras, registrado dia 27 de agosto de 2009 na Reserva Biológica das Perobas (A). S. melanoleucus carregando um preá (Cavia aperea) nas garras, registrado dia 14 de março de 2011 na Fazenda Monte Alegre, Telêmaco Borba (B).

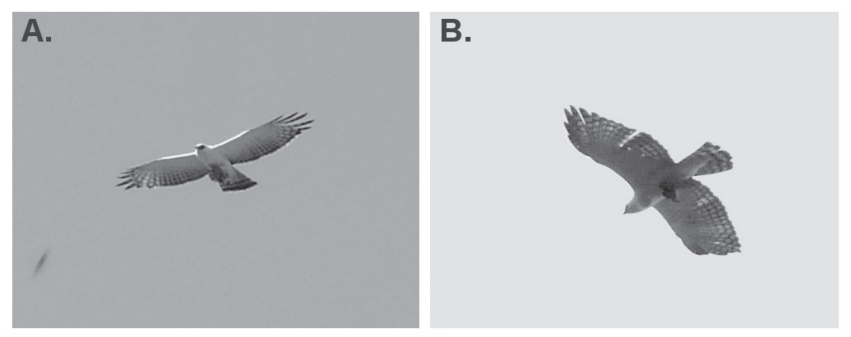

\section{Discussão}

Segundo Willis (1988) a captura de mamíferos é pouco frequente na espécie, e em ambos os registros de captura de mamíferos o $S$. melanoleucus estava voando em área aberta, sugerindo que a ave forrageia com certa frequência em áreas semiabertas, como campos, savanas e pastagens, onde pode capturar pequenos mamíferos e outros animais. São escassas as informações sobre a técnica de caça da espécie, o comportamento observado descrito como "voo montanha russa", sobrevoando a copa das árvores, é usado principalmente para a captura de aves, que é o item alimentar preferencial da espécie (WILLIS 1988; FERGUSON-LEES; CHRISTIE, 2001).

S. Melanoleucus parece voar com mais frequência entre às 11:00 e 14:00 h, horário na qual surgem as correntes de ar quente, aproveitadas pela ave para ganhar a altura e sobrevoar as áreas de caça. Portanto, essa é a melhor faixa de 
horário para a detecção da espécie na região. Vale ressaltar que na maioria dos registros, o gavião voava a grande altura, desaparecendo em poucos minutos, podendo facilmente passar despercebido por observadores menos atentos. Em voo a grande altura, pode ser confundido com outros gaviões comuns, como o gavião-de-cauda-curta (Buteo brachyurus). Segundo Willis (1988), o B. brachyurus também possui técnicas de caça parecidas com a do $S$. melanoleucus, aumentando a probabilidade de confusão com a espécie.

\section{Conclusão}

Com base nos dados obtidos, o $S$. melanoleucus aparenta ser raro, discreto e com baixas densidades populacionais na região, podendo ser facilmente subamostrado em levantamentos ornitológicos tradicionais, necessitando de métodos específicos para sua detecção, como é o caso dos pontos fixos.

Os registros dessa águia rara, residente e estritamente florestal nessas regiões do Paraná ressalta a importância da manutenção dos últimos remanescentes da Floresta Estacional e Ombrófila Mista para a conservação e manutenção das populações residuais da espécie. Informações sobre a biologia, comportamento e estratégias de caça do S. melanoleucus são fundamentais para o entendimento das relações da espécie com o ecossistema e revela necessidades básicas para sua sobrevivência, podendo auxiliar estratégias de conservação com esse e outros táxons.

\section{Agradecimentos}

Agradeço ao Jorge Albuquerque, Jessica M. Nascimento e Bruno Castelo B. Damiani pelas sugestões, ao ICMBio e a equipe da Reserva Biológica das Perobas: Carlos de Giovanni (in memorian), Antônio Guilherme e Deusdeti pelo convite da pesquisa, pelo apoio e ajuda em campo. Agradeço também ao Jean Ferreira Copatti pela companhia em muitas das saídas a campo.

\section{Referências}

ALVES, M. A. et al. Aves. In: BERGALLO, C. F. D. et al. (orgs.) A fauna ameaçada de extinção do estado do Rio de Janeiro. p. 113-124. Rio de Janeiro: Universidade do Estado do Rio de Janeiro, 2000.

ANJOS, L. Consequências biológicas da fragmentação no norte do Paraná. Instituto de Pesquisa e Estudos Florestais, Curitiba, v. 12, p. 87-94, 1998.

ANJOS, L.; SCHUCHMANN, K. L.; BERNDT, R. A. Avifaunal composition, species richness, and status in the Tibagi River Basin, Parana State, southern Brazil. Ornitologia Neotropical, Victoria, v. 8, p. 145-173, 1997.

DRUMMOND, G. et al. Listas das espécies da flora e da fauna ameaçadas de extinção do estado de Minas Gerais. Belo Horizonte: Fundação Biodiversitas, 2008.

FERGUSON-LEES, J.; CHRISTIE, D. A. Raptors of the World. Boston: Houghton Miffling Company, 2001. 992 p.
FULLER, M.; MOSHER, J. A. Raptor survey techniques, p. 37-66. In: PENDLETON, B. A. G. et al. (eds.) Raptor management techniques manual. Washigton: National Wildlife Federation, 1987. 420 p.

\section{INSTITUTO CHICO MENDES DE CONSERVAÇÃO} DA BIODIVERSIDADE - ICMBIO. Plano de manejo da Reserva Biológica das Perobas. Brasília: ICMBIO, 2012. $198 \mathrm{p}$.

MAGALHÃES-JUNIOR, C. A. O.; ORTÊNCIOFILHO, H.; DELARIVA, R. L. Reserva Biológica das Perobas - uma ilha de biodiversidade no noroeste paranaense. Curitiba: Instituto tecnológico de transportes e infraestrutura, 2014. $73 \mathrm{p}$.

MARQUES, A. A. B. et al . Lista de referência da fauna ameaçada de extinção no Rio Grande do Sul. Decreto no 41.672, de 11 junho de 2002. Porto Alegre: FZB/MCTPUCRS/PANGEA, 2002. 52p.

MENQ, W.; DELARIVA, R. L. Aves de rapina (Cathartiformes, Accipitriformes, Strigiformes e Falconiformes) na Reserva Biológica das Perobas, Paraná, Brasil, e seu entorno. Biotemas, Florianópolis, v. 28, n. 4, p. 145-154. 2015.

MIKICH, S. B.; BÉRNILS, R. S. Livro vermelho da fauna ameaçada no estado do Paraná. Curitiba: Instituto Ambiental do Paraná, 2004. 763 p.

REIS, N.R. et al. Riqueza de espécies de morcegos (Mammalia, Chiroptera) em dois diferentes habitats, na região centro-sul do Paraná, sul do Brasil. Revista Brasileira de Zoologia, Curitiba, v. 23, n. 3, p. 813-816. 2006.

RODERJAN, C. V. et al. As regiões fitogeográficas do estado do Paraná. Revista Ciência e Ambiente, Santa Maria, v. 24, p. 75-92. 2002.

SICK, H. Ornitologia brasileira. Rio de Janeiro: Nova Fronteira, 1997. 912 p.

SIQUEIRA, E. L. WA419675, Spizaetus melanoleucus (Vieillot, 1816). Wiki Aves. Disponível em: < http://www. wikiaves.com/419675 >. Acesso em: 07 Abr. 2015.

SILVEIRA, L. F. et al. Aves. In: BRESSAN, P. M.; KIERULFF, M. C.; SUGIEDA, A. M. Fauna ameaçada de extinção no estado de São Paulo: Vertebrados. São Paulo: Fundação Parque Zoológico de São Paulo e Secretaria do Meio Ambiente, 2009. 645 p.

SIMON, J. E. et al. As aves ameaçadas de extinção no estado do Espírito Santo. In: MENDES, S. L.; PASSAMANI, M. (Org.). Livro vermelho das espécies da fauna ameaçada de extinção no estado do Espírito Santo, Vitória: Ipema, 2007. 140 p.

STRAUBE, F. C.; URBEN-FILHO, A. avifauna da Reserva 
Natural Salto Morato (Guaraqueçaba, Paraná). Atualidades Ornitológicas, Ivaiporã, v. 124, p. 12, 2005.

WILLIS, E. O. A hunting technique of the Black-and-white Hawk-eagle (Spizastur melanoleucus). Wilson Bulletin, Waco, v. 100, p. 672-675, 1988.

Recebido em: 13.04.2015

Aceito em: 22.10.2015 